\title{
LATE PROSTHETIC VASCULAR GRAFT INFECTIONS AFTER RECONSTRUCTIONS ON AORTOILIAC SEGMENT: AN ELEVEN YEARS EXPERIENCE
}

\section{Lyubomir Ts. Beshev, Valentina E. Edreva- Besheva ${ }^{1}$, Mariya P. Sredkova', Dobromir D. Nguen ${ }^{2}$}

\author{
Department of Vascular Surgery \\ ${ }^{1}$ Department of Microbiology and \\ Medical Genetics \\ ${ }^{2}$ Student, Faculty of Medicine \\ Medical University - Pleven
}

Corresponding Author:

Lyubomir Ts. Beshev

Department of Vascular Surgery

Medical University - Pleven

1, St. Kliment Ochridski str.

5800, Pleven

Bulgaria

e-mail:lyubomir_beshev@yachoo.com

Received: January 25, 2013

Revision received: February 18, 2013

Accepted: June 26, 2013

\section{Summary}

The purpose of the study was to evaluate the frequency and etiology of late prosthetic vascular graft infections after reconstructions on aortoiliac segment. From 2001 to 2011, 545 primary reconstructions were performed on 545 consecutive patients. We had 18 cases of late intracavitary graft infections in 14 of them. A total of 58 clinical specimens collected from patients before, during and after reoperation were analyzed. Pathogens were isolated using conventional methods for aerobic and anaerobic bacteria. The isolates were identified down to species level by conventional biochemical methods, VITEK 2 and mini API Systems (bioMereux, France). During an 11-year period after prosthetic grafting of the abdominal aorta and aortoiliac segment the incidence of late (more than 4 months after implantation) infection was $3.11 \%$. The mean interval between the initial operation and development of infection was 39.2 months (range 4 to 84 ). Positive microbial cultures were found in 46 clinical specimens. A total of 66 microbial isolates were cultured, comprising 27 clinical strains. Gram-positive bacteria were predominant - $15(55.55 \%)$ strains, followed by Gram-negative bacteria - 9 (33.33\%), Candida albicans$2(7.4 \%)$ and Bacteroides fragilis - $1(3.7 \%)$. In 7 cases, the infection was monobacterial, caused predominantly by Staphylococcus species. In the rest of the cases, the infections were polymicrobial, caused by association between two microbial species. Mortality rate was $35.71 \%$ ( 5 cases ) - in 4 of them the infection was caused by association between two species of Gram-negative bacteria or between Gram-negative bacteria and Candida albicans. The incidence of late intracavitary vascular graft infection was low. The average period for development of this complication was about 3 years after reconstruction. Among the causative agents, Gram-positive microorganisms had a predominant role but infections caused by Gram-negative bacteria, especially when they were in association, had a worse outcome.

Key words: vascular graft, aortoiliac segment, late infection

\section{Introduction}

Infection of a vascular prosthesis is a relatively uncommon, but probably the most serious complication of vascular surgery that may occur 
after implantation and dramatically affect outcome [1].

Despite aggressive antibiotic administration, surgical treatment and a complex of antiseptic precautions, overall mortality rates in aortic graft infection remain between 10 and $50 \%$, and overall amputation rates range between 15 and $60 \%$ [2].

It is commonly agreed that prosthetic graft infection should be classified as early $(<4$ months after graft implantation) and late $(>4$ months after graft implantation) [3].

The purpose of this study was to evaluate the etiology and epidemiology of late vascular graft infection in patients treated in Department of Vascular Surgery of University Hospital of Pleven for an 11-year period and evaluate correlation between causative organisms and outcome.

\section{Patients and Methods}

\section{Population}

From January 1, 2001 to December 31, 2011, a total of 14 patients with 18 episodes of late prosthetic graft infection were treated in the Department of Vascular Surgery, University Hospital - Pleven. The initial operation was performed to treat atherosclerotic aortoiliac occlusive disease or aortic aneurysm. The primary procedures were aortobifemoral, aortofemoral or aortoiliac reconstructions. The average age of the patients was 64.3 years (range 49-78 years) and the men: women ratio was 13:1.

\section{Methods}

The diagnosis of prosthetic graft infection was based on patient history, clinical examination, laboratory tests, microbiological findings, ultrasonography and computed tomography in all patients. Fibrogastroscopy was performed in two cases. The digital subtraction angiography or computed tomography angiography were performed in all patients indicated for reoperation.

Bacteriological tests were performed for all 18 cases. A total of 58 specimens for microbiological examination were collected preoperatively, intra-operatively and postoperatively. Specimens for bacteriological culture were collected by aspiration with a needle and syringe (blood for blood culture, serous and purulent fluids around prosthesis, pus, drainage), or by excision and biopsy (pieces of infected tissue or prosthesis). Swabs were rarely used (Table 1).

Table 1. Type of specimen for microbiological examination

\begin{tabular}{llll}
\hline Specimen & With bacterial growth & No growth & Total \\
\hline Pieces of prostheses & 11 & 1 & 12 \\
\hline Periprosthetic tissue & 6 & 3 & 9 \\
\hline Wound discharge & 18 & 3 & 21 \\
\hline Lavage fluid & 3 & 2 & 5 \\
\hline Blod culture & 4 & 2 & 6 \\
\hline Drainage & 3 & - & 3 \\
\hline Fistulas & 1 & 1 & 2 \\
\hline Total & $\mathbf{4 6}$ & $\mathbf{1 2}$ & $\mathbf{5 8}$ \\
\hline
\end{tabular}

All specimens were inoculated onto blood agar (5\% sheep blood), eosin-methylene blue agar and trypticase soy broth for aerobic incubation and onto Schaedler agar for anaerobic incubation.

Blood cultures were performed with BACTEC 9200 System (Becton Dickinson, USA). The isolates were identified down to species level by conventional biochemical methods, VITEK 2 and mini API Systems (bio Merieux, France). Antimicrobial susceptibility testing was performed by agar diffusion test or by determination of minimum inhibitory concentrations.

\section{Results}

Table 2 shows the demographic characteristics and clinical features of our patients.

Of the 14 patients included in the study, 13 were male. The mean age of the patients was 64.3 years (range $49-78$ years). 
_ Beshev L. et al. Late prosthetic vascular graft infections after reconstructions on aortoiliac segment...

Table 2. Demographic characteristics and clinical features of patients

\begin{tabular}{llllll}
\hline Initials & Age & Sex & Primary reconstruction & Time until complication & Type of complication \\
\hline HKH & 52 & $\mathrm{~m}$ & Bypass aorto-bifemoralis & 36 months & Abscessus paraprosthesis \\
\hline HKH* & 53 & $\mathrm{~m}$ & Bypass aorto-bifemoralis & 6 months & Abscessus paraprosthesis \\
\hline VSA & 58 & M & Bypass aorto-biiliacus & 32 months & $\begin{array}{l}\text { Absc. paraprosth. Sepsis. } \\
\text { Fistula prostheso-coecalis }\end{array}$ \\
\hline EVE & 53 & $\mathrm{~m}$ & Bypass aorto-bifemoralis & 48 months & Suppuratio prosthesis \\
\hline EVE* & 56 & $\mathrm{~m}$ & Bypass aorto-bifemoralis & 44 months & Abscessus paraprosthesis \\
\hline NIN & 63 & $\mathrm{~m}$ & Bypass aorto-bifemoralis & 24 months & Fistula paraprosthesis \\
\hline NIN* & 66 & $\mathrm{~m}$ & Bypass aorto-bifemoralis & 45 months & Fistula paraprosthesis \\
\hline GAP & 59 & $\mathrm{~m}$ & Bypass aorto-bifemoralis & 84 months & Abscessus paraprosthesis \\
\hline NAD & 49 & $\mathrm{~m}$ & Bypass aorto-bifemoralis & 34 months & Abscessus paraprosthesis \\
\hline BSE & 68 & $\mathrm{~m}$ & Bypass aorto-bifemoralis & 48 months & Abscessus paraprosthesis \\
\hline NTN & 66 & $\mathrm{~m}$ & Bypass aorto-bifemoralis & n.d. & Abscessus paraprosthesis \\
\hline AKC & 55 & $\mathrm{~m}$ & Bypass ao-femoralis sin. & 36 months & Abscessus paraprosthesis \\
\hline AKC* & 57 & M & Bypass ao-femoralis sin. & 60 months & Abscessus \\
& & & & & paraprosthesis.Sepsis \\
\hline PTT & 64 & $\mathrm{~m}$ & Bypass ilio-femoralis & 4 months & Abscessus paraprosthesis \\
\hline MTP & 71 & $\mathrm{~m}$ & Bypass aorto-bifemoralis & 30 months & Fistula aorto-duodenalis \\
\hline MVK & 63 & $\mathrm{~m}$ & Bypass aorto-bifemoralis & 36 months & Fistula aorto-duodenalis \\
\hline IDH & 78 & $\mathrm{~m}$ & Bypass ilio-fem-poplitealis & 36 months & Fistula ao-duoden. Sepsis. \\
\hline EIM & 63 & F & Bypass aorto-bifemoralis & 24 months & \\
\hline & & & & &
\end{tabular}

* one patient with 2 episodes of infection in different time after primary reconstruction

Ten patients developed only one episode of infection after the primary reconstruction. Each of the other four patients developed two episodes of infection in different time periods after primary reconstruction. The mean interval between initial operation and development of infection was 39.2 (range 4 to 84 ) months. The incidence of late prosthetic graft infection in this study was $3.11 \%$. This complication occurred after 545 primary reconstructions on aortoiliac segment performed during the study period. The frequency of this complication was relatively low in comparison with other complications after reconstructions in this area, such as thrombosis of prosthesis or development of anastomotic aneurysms (Figure 1).

The clinical presentations of intracavitary graft infection varied. In the majority of the cases (12), paraprosthetic abscesses occurred. Focal wound infection, fluid collection or draining sinus tract (fistulas) occurred in 6 cases, prosthetic-duodenal or prosthetic-enteral fistulas and erosions - in 4 cases (Figure 2); and sepsis in 3 cases.

Positive bacterial findings were registered in
46 samples. A total of 66 microbial isolates were cultured (Table 3), comprising 27 clinical strains. Gram-positive bacteria were predominant - 15 strains $(55.55 \%)$, followed by Gram-negative bacteria -9 strains $(33.33 \%)$, yeasts $-2(7.4 \%)$ and anaerobic bacteria - 1 (3.7\%) (Figure 3). Staphylococcus aureus was the most common Gram-positive organism cultured, followed by beta-haemolytic streptococci, enterococci, Streptococcus viridans and diphtheroids. Among Gram-negative bacteria, members of family Enterobacteriaceae were predominant (7 strains), followed by other Gram-negative rods as Pseudomonas aeruginosa and Acinetobacter baumannii.

In one of the episodes the results from microbiological examination remained negative. The infection was monobacterial in 7 cases (Table 4). Gram-positive microorganisms played a predominant role in the cases with monobacterial infections ( 5 out of 7 cases). The dominant pathogen was S.aureus (3 out of 5 cases). There were no lethal outcomes in the cases with mono-bacterial infection. In the rest ten cases, the infection was polymicrobial, 


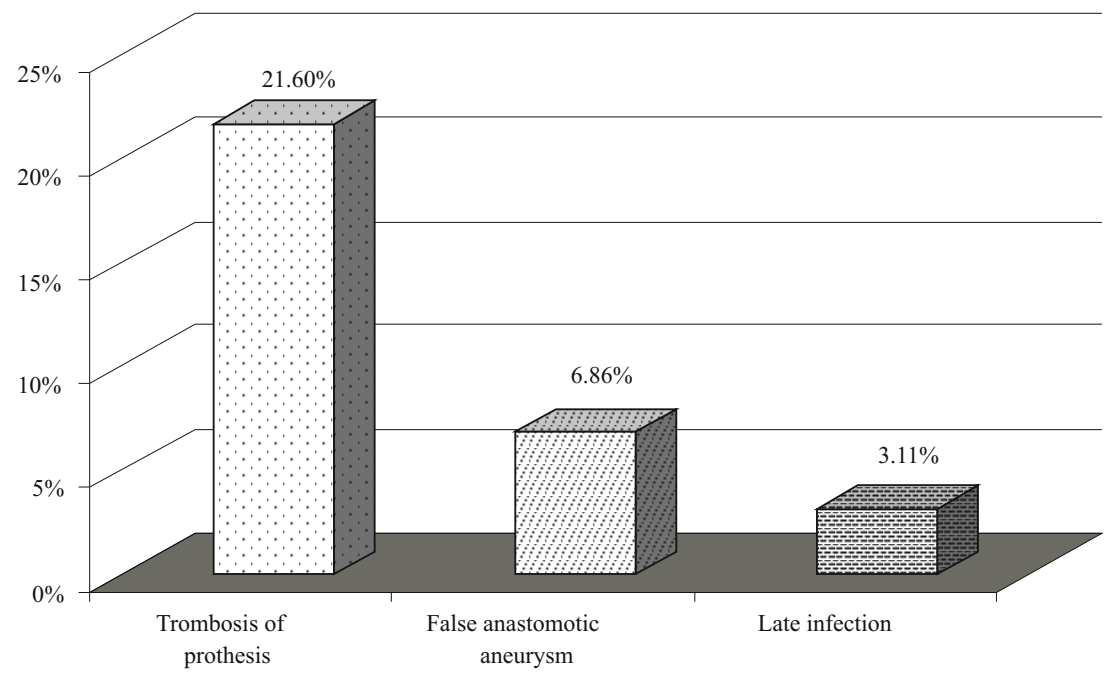

Figure 1. Frequency of complications after reconstructions of AOIS

Table 2. Demographic characteristics and clinical features of patients

\begin{tabular}{llllll}
\hline Initials & Age & Sex & Primary reconstruction & Time until complication & Type of complication \\
\hline HKH & 52 & $\mathrm{~m}$ & Bypass aorto-bifemoralis & 36 months & Abscessus paraprosthesis \\
\hline HKH* & 53 & $\mathrm{~m}$ & Bypass aorto-bifemoralis & 6 months & Abscessus paraprosthesis \\
\hline VSA & 58 & M & Bypass aorto-biiliacus & 32 months & $\begin{array}{l}\text { Absc. paraprosth. Sepsis. } \\
\text { Fistula prostheso-coecalis }\end{array}$ \\
\hline EVE & 53 & $\mathrm{~m}$ & Bypass aorto-bifemoralis & 48 months & Suppuratio prosthesis \\
\hline EVE* & 56 & $\mathrm{~m}$ & Bypass aorto-bifemoralis & 44 months & Abscessus paraprosthesis \\
\hline NIN & 63 & $\mathrm{~m}$ & Bypass aorto-bifemoralis & 24 months & Fistula paraprosthesis \\
\hline NIN* & 66 & $\mathrm{~m}$ & Bypass aorto-bifemoralis & 45 months & Fistula paraprosthesis \\
\hline GAP & 59 & $\mathrm{~m}$ & Bypass aorto-bifemoralis & 84 months & Abscessus paraprosthesis \\
\hline NAD & 49 & $\mathrm{~m}$ & Bypass aorto-bifemoralis & 34 months & Abscessus paraprosthesis \\
\hline BSE & 68 & $\mathrm{~m}$ & Bypass aorto-bifemoralis & 48 months & Abscessus paraprosthesis \\
\hline NTN & 66 & $\mathrm{~m}$ & Bypass aorto-bifemoralis & n.d. & Abscessus paraprosthesis \\
\hline AKC & 55 & $\mathrm{~m}$ & Bypass ao-femoralis sin. & 36 months & Abscessus paraprosthesis \\
\hline AKC* & 57 & M & Bypass ao-femoralis sin. & 60 months & Abscessus \\
& & & & paraprosthesis.Sepsis \\
\hline PTT & 64 & $\mathrm{~m}$ & Bypass ilio-femoralis & 4 months & Abscessus paraprosthesis \\
\hline MTP & 71 & $\mathrm{~m}$ & Bypass aorto-bifemoralis & 30 months & Fistula aorto-duodenalis \\
\hline MVK & 63 & $\mathrm{~m}$ & Bypass aorto-bifemoralis & 36 months & Fistula aorto-duodenalis \\
\hline IDH & 78 & $\mathrm{~m}$ & Bypass ilio-fem-poplitealis & 36 months & Abscessus paraprosthesis \\
\hline EIM & 63 & F & Bypass aorto-bifemoralis & 24 months & Fistula ao-duoden. Sepsis. \\
& & & & Bleeding - GIT \\
\hline
\end{tabular}

* one patient with 2 episodes of infection in different time after primary reconstruction

caused by association between two types of microorganisms (Table 5). The polymicrobial infection was caused by two types of Gram- positive microorganisms in 5 cases. Association between Gram-positive and Gram-negative bacteria was established in one case, and 
Beshev L. et al. Late prosthetic vascular graft infections after reconstructions on aortoiliac segment...

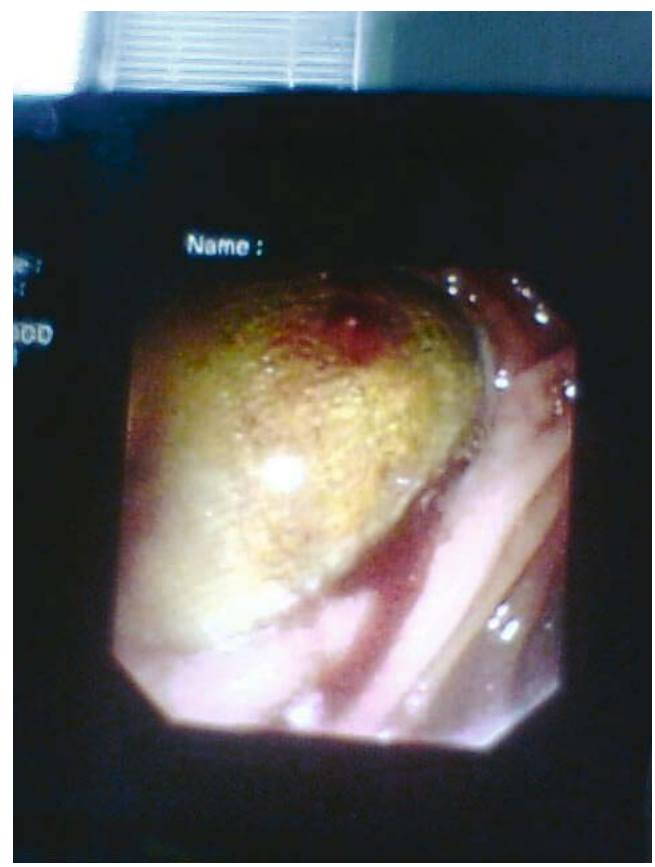

Figure 2. Fistula proteso-dudenalis (fibrogastroscopy) between Gram-negative bacteria and yeasts - in another case. In three cases, there was association between two types of Gram-negative bacteria.

The clinical manifestation was more severe and with signs of sepsis in cases of association, formed by two types of Gram-negative microorganisms. In one case, where the causative agent identified was P.aeruginosa, the colloid cover in the infected segment of prosthesis was totally destroyed (Figure 4). In the cases with Candida albicans, the clinical signs of the infection were fistula protheso-coecalis or aortoduodenalis.

Five perioperative deaths were related to graft infection; the other death was due to an unrelated cause (acute myocardial infarction). Overall, $35.71 \%$ of the perioperative mortality rate in our study was related to infection. In four of the five cases with exitus letalis, the infection was caused by microbial association between two types of Gram-negative bacteria, or between Gramnegative bacteria and Candida albicans.

Table 3. Bacteriology of prosthetic vascular graft infection (isolates from 46 collected specimens with bacterial growth)

\begin{tabular}{lllllllll}
\hline Isolates & Prosthesis & Tissue & Wound & Lavage & Blood & Drainage & Fistulas & Total \\
\hline S.aureus & 3 & 0 & 8 & 1 & 2 & 0 & 1 & 15 \\
\hline S.epidermidis & 0 & 0 & 1 & 0 & 0 & 0 & 0 & 1 \\
\hline Str. nonAnonB & 1 & 0 & 2 & 0 & 0 & 0 & 0 & 3 \\
\hline S.agalactiae & 1 & 0 & 1 & 1 & 0 & 0 & 0 & 3 \\
\hline S.viridans & 1 & 0 & 1 & 0 & 0 & 0 & 0 & 2 \\
\hline E.faecalis & 1 & 0 & 2 & 0 & 0 & 0 & 0 & 3 \\
\hline E.casseliflavis & 0 & 0 & 2 & 0 & 0 & 1 & 0 & 3 \\
\hline C.xerosis & 0 & 0 & 1 & 0 & 0 & 0 & 0 & 1 \\
\hline E.coli & 1 & 0 & 0 & 0 & 0 & 0 & 0 & 1 \\
\hline K.pneumoniae & 1 & 3 & 1 & 1 & 1 & 1 & 0 & 8 \\
\hline E.cloacae & 4 & 2 & 2 & 0 & 1 & 2 & 0 & 11 \\
\hline C.freundii & 1 & 0 & 0 & 0 & 1 & 2 & 0 & 4 \\
\hline P.mirabilis & 0 & 0 & 1 & 1 & 0 & 0 & 0 & 2 \\
\hline P.aeruginosa & 1 & 0 & 0 & 0 & 0 & 0 & 0 & 1 \\
\hline A.baumannii & 0 & 0 & 1 & 0 & 0 & 0 & 0 & 1 \\
\hline B.fragilis & 1 & 0 & 0 & 0 & 0 & 0 & 0 & 1 \\
\hline C.albicans & 1 & 3 & 1 & 0 & 0 & 1 & 0 & 6 \\
\hline Total & $\mathbf{1 7}$ & $\mathbf{8}$ & $\mathbf{2 4}$ & $\mathbf{4}$ & $\mathbf{5}$ & $\mathbf{7}$ & $\mathbf{1}$ & $\mathbf{6 6}$ \\
\hline
\end{tabular}




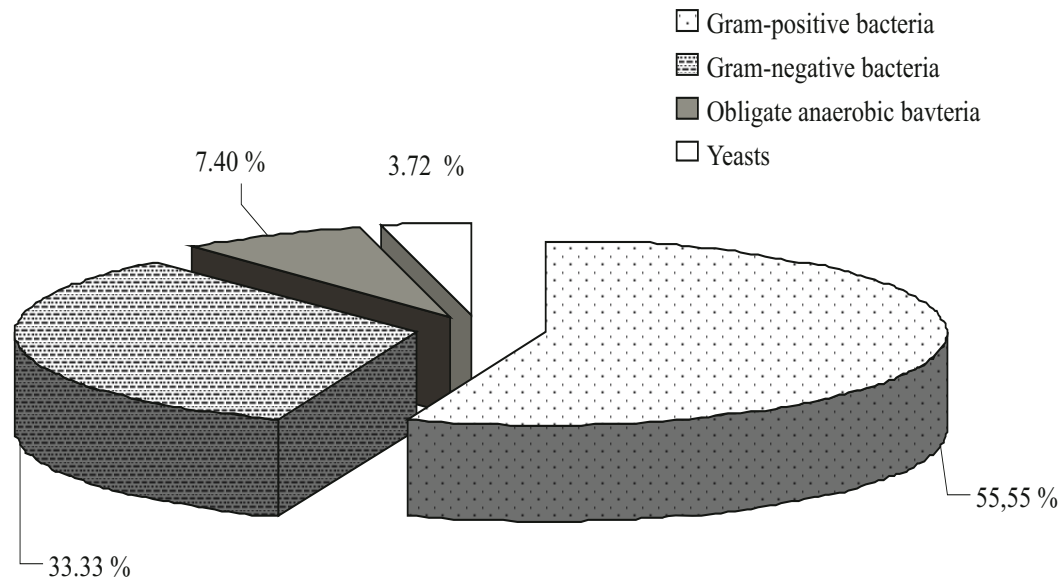

Figure 3. Microbial strains isolated from clinical specimens

Table 4. Etiological agents of monobacterial prosthetic graft infection

\begin{tabular}{llll}
\hline Initials & Microorganism & Time for development & Outcome \\
\hline NIN & S.aureus & 24 months & good \\
\hline NIN* & S.viridans & 45 months & good \\
\hline EVE & E.faecalis & 44 months & good \\
\hline NTN & E.cloacae & n.d. & good \\
\hline AKC & S.aureus & 36 months & good \\
\hline PTT & S.aureus & 4 months & good \\
\hline IDH & B.fragilis & 36 months & good \\
\hline
\end{tabular}

Table 5. Microorganisms isolated from patients with polymicrobial prosthetic graft infection

\begin{tabular}{llll}
\hline Initials & Microorganisms & Time for development & Outcome \\
\hline HKH & P.mirabilis + P.aeruginosa & 36 months & death \\
\hline VSA & K.pneumoniae + C.albicans & 32 months & death \\
\hline EVE & S.aureus + Strept.beta-haemolyt. & 48 months & good \\
\hline GAP & S.aureus + S.agalactiae & 84 months & good \\
\hline NAD & E.cloacae + E.coli & 34 months & death \\
\hline AKC & S.aureus + Strept.beta-haemolyt. & 60 months & death \\
\hline MPT & E.casseliflavus + C.albicans & 30 months & good \\
\hline MVK & S.epidermidis + C.xerosis & 36 months & good \\
\hline ACC & C.freundii + E.cloacae & 24 months & death \\
\hline
\end{tabular}




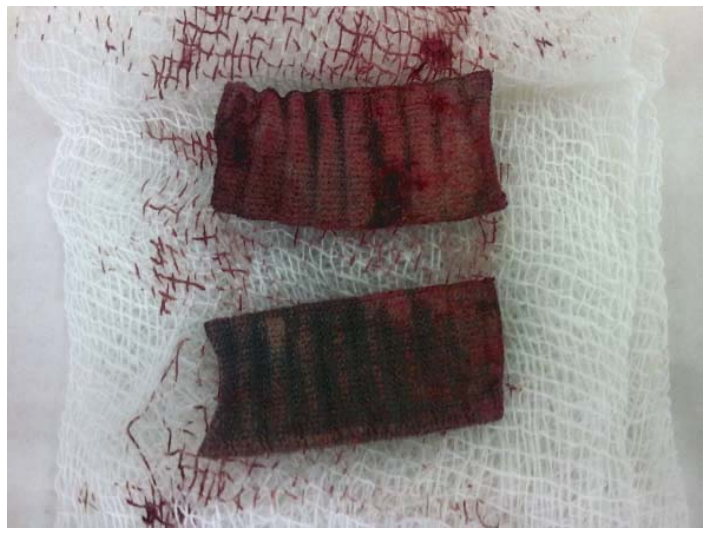

Figure 4. Destroyed colloid cover of prosthesis

\section{Discussion}

The reported incidence of infection involving vascular prosthesis varies. Infections occur after $0.2 \%$ to $5 \%$ of operations, and depends on implant site, indication for intervention, underlying disease, and host defense mechanisms [4]. Draus and Bergamini have reported frequency from $1 \%$ to $6 \%$ with an average of $2.1 \%$ [5]. Our results correlated with the ones cited above. In a comprehensive review, Linda Reilly cited data of Cilligaro [6] and Ricco [7]. They reported infection rates of less than $1 \%$ in cases of intra-abdominal aorto-aortic or aortoiliac bypass graft. However, she concluded that reported prosthetic vascular graft infection rates probably represented a minimal incidence, since complete patient follow-up is necessary to determine the actual rate, and such detailed follow-up is rare [8].

Virtually any microorganism is capable of infecting a synthetic graft, including some rare and unusual pathogens $[9,10]$. Early graft infections are usually caused by virulent hospitalacquired pathogens such as S.aureus, P.aeruginosa, members of the family Enterobacteriaceae. Late infections are due to graft colonization by "low-virulence" organisms such as Staphylococcus epidermidis or other coagulase-negative staphylococci or, infrequently, Candida species [4]. S.aureus has a predominant role in both types of infection [11, 12].

Our findings were in accordance with data cited above: in our study, Gram-positive bacteria were predominant $(55.55 \%)$ of all the pathogens that were isolated. However, our results suggest that Gram-negative bacteria have a significant share as etiological agents in case of late vascular graft infection. This conclusion is in contrast with a commonly accepted statement that these pathogens are causative agents predominantly in early infections [5].

Recently, Zetrenne et al. [13] reported that Gram-negative organisms were cultured in abundance $(45 \%)$ from isolates, which is in support of our results. Our data is in accordance with conclusions of Reilly, that, when an infected graft is aortic in location, the rate of recovery of coagulase-negative staphylococci and S.aureus declines and the rate of recovery of Gramnegative organisms increases. When an aortic graft infection is associated with an aorto-enteric fistula, the bacteriology of the infecting organism shifts even more notably to Gram-negative organisms [8]

This "shift" of microbial profile of late vascular graft infections is probably attributable to the fact that, in guidelines for prophylaxis and empiric therapy of this kind of infections, the drugs of choice are antibacterial agents against Gram-positive bacteria. This "shift" was prognosticated by Brun-Buisson about ten years ago [14].

Current literature suggests that polymicrobial infections have became significant in many cases [5]. In our group of patients there were ten cases of polymicrobial infections. We tried to find a correlation between the etiology of infection and patient's outcome. We observed poor outcome in cases of polymicrobial infections, caused by association between two types of Gram-negative bacteria.

In our study, the mortality rate was $35.71 \%$ ( 5 cases). In 4 of them, the infection was caused by association between Gram-negative bacteria and/or Candida. Only in 3 of the cases the same microorganisms were cultured simultaneously from the prosthesis and from blood cultures, which is in accordance with results reported by Bishart and Minuhin, i.e. in late infections of abdominal prosthetic vascular grafts the yield from blood cultures is lower [15].

$P$. aeruginosa is not among common causative agents of late vascular graft infection [13]. In our study, this pathogen was isolated only in one case, in association with Proteus mirabilis. Intraoperatively, we found total destruction of vascular tissue and the silver cover of prosthesis. These microorganisms elaborate the enzymes elastase and alkaline protease, which break down 
elastin, collagen, fibronectin and fibrin [12].

\section{Conclusion}

The incidence of late intracavitary vascular graft infections in our study correlated with data reported by other authors. The average period,

\section{References}

1. Carrel T, Schmidli J. Management of vascular graft and endoprostheric infection of the thoracic and thoraco-abdominal aorta. Multimed Man Cardiothorac Surg. [Internet] 2011; [cited 2013 Jan 12];2011(1101): [about 12 p.]. Available from:http://mmcts.oxfordjournals.org/content/20 11/1101/mmcts.2010.004705.full

2. Seeger JM, Back MR, Albright JL, Carlton LM, Harward TRS, Kubulis MS, et al. Influence of patient characteristics and treatment options on outcome of patients with prosthetic aortic graft infection. Ann Vasc Surg. 1999;13:413-20.

3. Bandyck DF. Infection of prosthetic vascular grafts. In: Rutherford RB, editor. Vascular Surgery. 5th ed. St. Louis: W.B. Saunders Co.;1995.

4. Bandyck DF, Back MR. Infection in prosthetic vascular grafts. In: Moore WS, editor. Vascular Surgery: a comprehensive review 6th ed. Philadelphia: WB Sanders; 2002:310-44.

5. Draus JM Jr, Bergamini TM. Vascular graft infections: epidemiology, microbiology, pathogenesis and prevention. In: Towne JB and Hallier LH, editors. Complications in Vascular Surgery. 6th ed. New York: Marcel Dekker Inc; 2004. p. 305-16.

6. Calligaro KD, Veith FJ. Diagnosis and management of infected prosthetic aortic graft. Surgery. 1991;110(5):805-13.

7. Ricco JB. InterGard silver bifurcated graft: features and results of a multicenter clinical study. J Vasc Surg. 2006;44(2):339-46.

8. Reilly LM. Prosthetic vascular graft infection. In: Hallet JM, Mills JL, Earnshaw JJ, Reekers JA, Rooke TW, editors. Comprehensive Vascular and Endovascular Surgery. 2nd ed. Philadelphia: PA,Mosby;2009.p.688-713. during which infections developed, was about 3 years. Among the causative agents, Grampositive microorganisms had a predominant role but infections caused by Gram-negative bacteria, especially when they were in association, had a worse outcome.

9. Clerc O, Jaton K, Prodhom G, von Segesser L, Greloz V, Greub G. Mycobacterium tuberculosis aortic graft infection with recurrent hemoptysis: a case report. J Med Case Rep. 2008;2:233.

10. Rohde H, Horstkotte MA, Loeper S, Aberle J, Jenicke L, Lampidis R, Mack D. Recurrent Lysteria monocytogenes aortic graft infection: confirmation of relapse by molecular subtyping. Diagn Microbiol Infect Dis.2004;48(1):63-7.

11. Carpenter CF, Swami S. Vascular Graft Infections. In: Bartlett JG, Auwaerter PG, Pham PA, editors. Johns Hopkins University Antibiotic Guide. 2008. Available from: http://www.hopkins-abxguide.org

12. Clagett GP. Aortic graft infection. In: Towne JB, Hallier L, editors. Complication in Vascular Surgery. 6th ed. New York: Marcel Dekker Inc; 2004.p. 317-36.

13. Zetrenne E, Mc Intosh BC, Mc Rae MH, Gusberg R, Evans GRD, Naravan D.Prosthetic vascular graft infection: A multicenter review of surgical management. Yale J Biol Med. 2007;80(3):113-21.

14. Brun-Buisson C. Changes in bacterial spectrum in vascular surgery: should we modify our prophylaxis policy? In: Becquemin J-P, Loisane D, Watelet $\mathrm{J}$, editors. Controversies and update in vascular and cardiovascular surgery. Torino: Edizioni Minerva Medica; 2003. p. 3-7.

15. Bishart N, Minuhin I. Prosthetic vascular graft infections between blood and concordance of graft culture pathogen. Am J Med Sci. 2012; 344(6):431-5. 